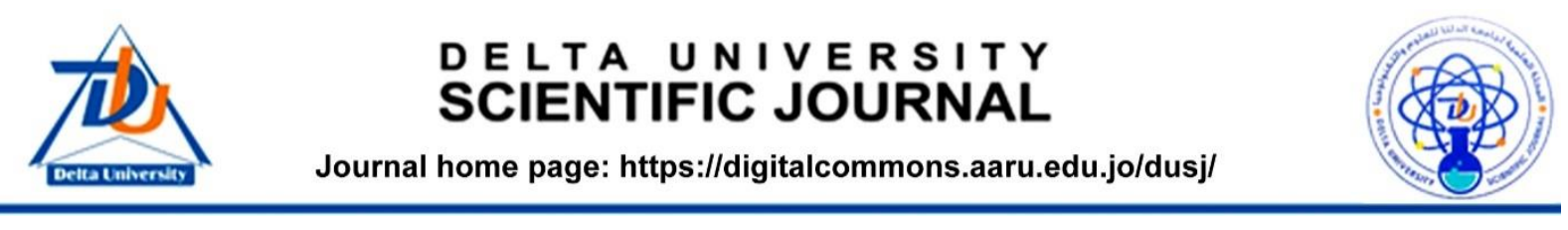

\title{
The Impact of Covid-19 pandemic on Bank Performance: Evidence from Listed Banks on the Egyptian Stock Exchange
}

\author{
Mohamed Zaki Balboula, ${ }^{* 1}$ Maha Saad Metawea ${ }^{2}$ \\ 1 Department of accounting, Faculty of Business Administration, Delta University. \\ 2 Department of Business Administration, Faculty of Business Administration, Delta University.
}

Keywords:

1- Covid-19

2- Stock return

3- Stock return volatility

4- Banking system

\begin{abstract}
This study investigates the impact of Covid-19 pandemic on the risk and return of Egyptian banks. It measures bank performance using stock volatility (as a measurement of risk) and stock returns. As well as, it measures Covid-19 using "confirmed new cases", "confirmed new deaths" and "mortality growth rate" on a weekly basis. We use one-year lagged leverage, bank size and return on assets as control variables. The study applies Pooled OLS regression, Pearson correlation and Paired sample t-test in order to statistically investigate the proposed hypotheses. The sample consists of 12 banks listed on the Egyptian Stock Exchange (out of 14), covering two periods of equal length of time, sixteen weeks before and during the Covid-19 pandemic. Our analysis reveals that new cases, new deaths and mortality growth rate of Covid-19 are negatively (positively) related to stock returns (volatility). However, Egyptian banks' stock returns and volatility are more sensitive to new cases and deaths of Covid-19 than mortality growth rate.
\end{abstract}

\section{INTRODUCTION}

The banking system has been considered a vital tool in achieving economic welfare in each country. Literature pointed that a good bank can boost more lending and decrease transaction fees. (Nguyen,2020). Bank performance is highly important for different parties such as investors, managers, employees, customers, and regulators and examiners. For investors, it is a key determinant of the bank stock price. The study of stock return can be useful for both domestic and global investors in the formation of investment strategies that aim at reducing their investment risk and increasing their potential returns. Markets that exhibit more stability are likely to be more attractive to local investors and create new opportunities for cross border investors. Furthermore, bank performance is an important tool for bank managers to make strategic decisions related to capitalize on bank strengths and overcome bank weaknesses. As well as, it is a critical indicator for regulators and examiners about the bank safety and stability, which considered a key pillar in the soundness of the banking system. Moreover, it is considered as a safety valve for bank employees' job security and a significant indicator for the safety of customer deposits. (Cetorelli\&Gambera, 2001; Beck \& Levine, 2004).

Coronavirus disease is an unexpected health crisis that is impacting the global financial markets. It speedily expanded to be a global emerging public health crisis. Accordingly, the World Health Organization on March 11, declared COVID-19 as a pandemic (World Health Organization, 2020). COVID-19 pandemic 
exposes firms to a variety of stiff challenges all at the same time. Baker et al. (2020) and Baker et al. (2020a) have argued that COVID-19 has a greater influence on the equity market than the old generation epidemic diseases such as Ebola, SARS, swine flu, and bird flu. There is clear evidence for a strong relationship between COVID-19 infections and stock market responses (Alfaro et al., 2020; Hassan et al., 2020) on the one side. On the other side, COVID-19 has also created an enormous increase in economic uncertainty. The degree of the crisis resilience of a firm could vary substantially depending on the stage of the unfolding crisis. Remarkably, the COVID-19 outbreak has made an unexpected, transitory, sharp deficiency in income for firms in numerous industries (Song et al., 2020).

According to Ramelli\& Wagner (2020); Song et al. (2020) Covid-19 pandemic has a major effect on real economic activity, and as a result of the uncertainty surrounding its variables such as (mortality rate, disease spread, and severity) this effect is still unclear. The majority of recent studies in the field of business have investigated the effect of COVID-19 on stock market performance. Most of these studies either focus on global trading on stock markets, grouping emerging and developed stock markets, or developed stock markets. However, few studies have examined the impact of covid-19 on firm-level performance. Knowing the performance of banks during Covid-19 pandemic period is not only important for investors and customers but is also useful for regulators and bank managers in formulating appropriate policies to mitigate the negative effects of this pandemic and improve the situation of the Egyptian banking sector.

Financial performance for all banks used to be measured by a combination of financial ratios analysis such as ROE, ROA, and Tobin-Q or by benchmarking and sometimes measuring performance relevant to budget or a combination of all the proxies (Avkiran,2000). Our study focus on bank performance from the perspective of bank risk and stock return. In this context, we attempt to clarify empirically whether Covid-19 pandemic exposes banks to more risk and leads to lower performance during this pandemic period. Based on this, we examine the differences between weekly stock returns and stock returns' volatility of the Egyptian banks before and during Covid-19 pandemic. Moreover, we investigate the impact of this pandemic on both Egyptian banks' stock returns and volatility.

This study derives its power from the fact that there's little literature concerning about the effect of Covid-19 pandemic on banking sector stock return. Moreover, there's a shortage of covering the MENA Region area especially Egypt in the reaction of its stock return as a result of Covid-19 pandemic.

The rest of this study is arranged as follows. In section 2 we present the literature review and research hypotheses. In section 3 outlines the samples data and methodology. In section 4 we present our empirical results and data analysis, and in Section 5 concludes the study.

\section{Literature Review and Hypotheses' Development}

Researchers have actively investigated the impact of covid-19 pandemic on the global markets. Khan, et al (2020), has examined the effect of COVID-19 pandemic on the stock markets exchanges of 16 countries. Results confirm that the weekly new cases of COVID-19 have a negative impact on the return in stock market. Moreover, investors in these countries don't respond to the media information on COVID-19 at the beginning stage of the pandemic. Alberto et al. (2020) has explored the financial stock exchanges' 
reaction to the COVID-19 pandemic in 64 countries over the period January 22 to April 17, 2020. The results show that financial stock exchanges reacted contrarily to the increase in COVID-19 cases. That is, stock market returns declines as the number of reported cases increase. Further, it shows that financial stock markets responses more proactively to the increase in the number of declared cases than the increase in the number of deaths.

However, other studies have focused on investigating which sectors have been severely affected by the outbreak. For example, Mieszko, et al. (2020) has explored the US securities exchange performance during COVID-19. The study has found that healthcare, food, natural gas, and software stocks gain high returns, while equity returns in petroleum, hospitality, entertainment, and real estate sectors fall significantly. In addition, loser stocks show extreme instability that relates adversely to stock returns. On the other hand, Bakas, (2020) Has examined the effect of economic uncertainty linked to worldwide pandemics on the volatility of the broad commodity price index and on the subindexes of crude oil and gold. The outcomes have demonstrated an adverse effect of pandemics on the volatility of commodity markets and particularly on the crude oil market, however, the impact on the gold market is positive and less significant.In addition, Abdelrhim et al., (2020) has found that the total deaths have more effect on the gold market, and the total cases had more impact on both silver and copper in the metals market. The outcomes additionally have demonstrated that there are no statistically significant differences between the return on investment for the metal markets and cryptocurrency markets during Covid-19.

Likewise, other studies have sought to investigate the reaction of countries' stock markets that have been severely affected by the pandemic. For example, Liu et al., (2020) has assessed the effect of the covid19 on twenty-one leading Stock Market indices in major affected countries including Japan, Korea, Singapore, The USA, Germany, Italy, and The UK. Their outcomes have demonstrated that the Stock Market fell rapidly after the virus outbreak. Also, countries in Asia experienced more negative abnormal returns than other countries. In addition, they have found a negative impact of Covid-19 cases on stock indices' abnormal returns by spreading investor's negative sentiment on future returns and fear of uncertainties.

On contrary, recent study has shown a positive linkage between Covid-19 and the stock markets. Sansa (2020) has investigated the impact of Covid-19 on the Financial Markets of Shanghai Stock Exchange and New York Dow Jones, from the period dated 1st of March 2020 to 25 March 2020. The findings reveal that there is a positive significant association between Covid-19 confirmed cases and the financial markets during the study period.

From the literature review, there is a shortage of studies that have explored the impact of covid-19 on firm-level performance. Since current studies either focus on global trading on markets, grouping emerging and developed markets, or developed markets. Furthermore, the shortcoming of examining the effect of the pandemic at the aggregate market level is that such an examination expects a homogeneous effect on sectorial performance. however, according to Narayan and Sharma (2011) sectors are heterogeneous and are probably going to respond in a different way to the Covid-19 pandemic. Moreover, there are a handful of studies exploring the effect of Covid-19 pandemic on banking sector performance.

Moreover, there's a shortage of covering the MENA Region area especially Egypt in the 
reaction of its stock returns as a result of Covid 19 pandemic. Therefore, this study contributes to the literature on the impact of Covid-19 pandemic on bank risk and return. By using comprehensive bank-level data mainly focused on the Covid-19 period, we are able to gain insights regarding how Covid-19 really influences bank performance.

Based on this, our main hypotheses can therefore be formulated as follows:

$\mathrm{H}_{1}$ : Egyptian bank's stock returns in the period pre-Covid-19is significantly different from period during Covid19.

$\mathrm{H}_{2}$ : Egyptian bank's stock return's volatility in the period pre-Covid-19 is significantly different from period during Covid-19.

$\mathrm{H}_{3}$ :There is a statistical significance impact of confirmed new cases, confirmed new deaths and mortality growth rate on Egyptian bank's stock returns.

$\mathrm{H}_{4}$ :There is a statistical significance impact of confirmed new cases, confirmed new deaths and mortality growth rate on Egyptian bank's stock returns volatility.

\section{Data and Methodology:}

\subsection{Model specification and variables}

$$
Y_{i, t}=\alpha+\beta_{1} \text { Covid }_{i . t}+\beta_{2} X_{i \text { Pre2020 }}+\varepsilon_{i, \tau}
$$

The dependent variable $Y_{i, t}$ denotes the bank performance measure, which is bank risk or bank's stock return, where the subscript $i$ denotes individual banks and $t$ denotes different weeks. We use the weekly stock return of bank $i$ from the last trading day in week $t-1$ and the weekly volatility of daily stock returns to measure bank risk and return. Stock return volatility is measured by the standard deviation of daily stock returns in week $t(C h e n$ et al., 2006). The independent variable Covid $_{i . t}$ is the Coronavirus (Covid-19) measurerepresenting confirmed new cases, confirmed new deaths and mortality growth rate on weekly basis. Confirmed new cases and deaths (NewCases, NewDeaths) are measured by the natural logarithm of the number ofnewcoronavirus cases and deaths in week $t$ (Wang et al., 2020). We use the natural logarithm of these variables to reduce the observed skewness. Mortality growth rate(MortGrowth)is measured by dividing the number ofnewcoronavirus deaths in week $t$ by the number of cumulative cases in the same week (Harjotoet al., 2020).

$X_{\text {iPre2020 }}$ Denotesone-year lagged control variables tocontrolthe differences in bank characteristics. These are leverage (Lev), bank Size (Size) and return on assets $(R O A) . L E V$ is the banks' debt ratio measured by the ratio of total debt to total assets, Size is the natural logarithm of the book value of total assets andROAis the ratio of net income to total assets.

\subsection{Sample and Data Sources:}

The study investigates 12 banks that represent all banks listed on the Egyptian Stock Exchange and have trading activity during the study period $(100 \%)$. As the Faisal Islamic Bank of Egypt (US Dollars) and Banque du Caire were excluded. The exclusion of the Faisal Islamic Bank of Egypt (US Dollars) is due to the fact the bank is listed twice in US dollars and Egyptian pounds. One of them was deleted as their reporting currency was not the Egyptian pound. On the other hand, Banque du Caire was excluded because it had no trading activity during the study period in the stock exchange.

We collect stock market data and accounting data of Egyptian banks from the official website of the Egyptian Stock Exchange (www.egx.com.eg) and (www.mubasher.info). Daily stock price data is used to calculate the weekly 
volatility and returns, while accounting data is used to determine differences in bank characteristics. We extract data on COVID19 from reports of the World Health Organization (WHO) available at (www.who.int).

Our data consist of two periods of equal length of time, sixteen weeks before and during the COVID pandemic. The first period starting from September 5, 2019, to December 30, 2019.
Considering matching Egypt Covid-19 data with the stock price data based on dates, the second period starting from Sunday, February 16, 2020, to June 10, 2020. Since Egypt announced its first Coronavirus infection on Friday, February 14, 2020, as Friday and Saturday are off-dayswith no trading.After deleting missing observations, our final sample data consists of 192 total observations.

Table 1. The banks sample of the study

\begin{tabular}{cc}
\hline Number\# & Bank Name \\
\hline 1. & Abu Dhabi Islamic Bank- Egypt \\
2. & Al Baraka Bank Egypt \\
3. & Commercial International Bank (Egypt) \\
4. & Credit Agricole Egypt \\
5. & Egyptian Gulf Bank \\
6. & Export Development Bank of Egypt (EDBE) \\
7. & Faisal Islamic Bank of Egypt - In EGP \\
8. & Housing \& Development Bank \\
9. & National Bank Of Kuwait- Egypt- NBK \\
10. & Qatar National Bank Alahly \\
11. & Societe Arabe Internationale De Banque (SAIB) \\
12. & Suez Canal Bank S.A.E \\
\hline
\end{tabular}

\section{Data Analysis and Results:}

The study analysis utilizes descriptive statistics and paired sample t-test to reveal the significance of the change. Pearson's correlation analysis examines the relationship between the study variables, and linear regression to identify the impact of the independent variables on the dependent variable. The outcomes from this analysis discuss the results to determine whether the hypotheses are supported.

\subsection{Results of Descriptive Statistics}

Table 2. summarizes the descriptive statistics of all variables in our study. The weekly Stock returns during the covid-19 pandemic (SR_During), has a mean of 0.051 with a standard deviation of 0.128 , ranging from -0.283 to 0.320 . While, stock returns before the pandemic (SR_Before) has a mean of 0.075 with a standard deviation of 0.115 , ranging from -0.069to 0.578. This indicates that the Egyptian banks' stock returns, on average, declines dramatically from positive $7.5 \%$ before the pandemic, to negative $5.1 \%$ during the pandemic.

Also, the descriptive analysis shows that the weekly volatility of stock returns during Covid-19 (Vol_During) ranges from 0to 3.606 along with a mean of0.472 and standard deviation of 0.627 . While,the volatility of stock returns before Covid-19 (Vol_Before) has a mean of 0.285 and standard deviation of 0.406 , ranging from0to 3.432. This shows that higher stock returns volatility on average during Covid19 period $(47.2 \%)$ than during pre-Covid19 period $(28.5 \%)$. It means that high level of fluctuation during Covid-19 period and high degree of uncertainty for investors. This is visualized in Figure1 and Figure 2. Figure 1. plots the weekly stock returns and volatility of Egyptian listed banks before 
Delta University Scientific Journal

Volume 4 Issue 1 April (2021)

the Covid-19 pandemic (from September 5 to December 30,2019) and during the (from February 16 to June 10, 2020). It can be clearly observed in Figure 1 that stock returns during covid-19 declines in comparison to the equal period before the covid-19 outbreak. Similarly, the second graph shown in Figure 2 reflects the stock returns' volatility behavior of Egyptian banks over the two sub-sample periods. It exhibits a higher stock return volatility during Covid-19 pandemic than the volatility after the pandemic.

Table 2. Descriptive statistics for all study variables

\begin{tabular}{ccccccc}
\hline & N & Range & Minimum & Maximum & Mean & Std. Deviation \\
\hline SR_During & 192 & 0.603 & -0.283 & 0.320 & -0.051 & 0.128 \\
SR_Before & 192 & 0.647 & -0.069 & 0.578 & 0.075 & 0.115 \\
Vol_During & 192 & 3.606 & 0.000 & 3.606 & 0.472 & 0.627 \\
Vol_Before & 192 & 3.432 & 0.000 & 3.432 & 0.285 & 0.406 \\
Newcase & 192 & 9033 & 0.000 & 9033 & 2006.813 & 2655.017 \\
NewDeath & 192 & 287 & 0.000 & 287 & 77.563 & 82.990 \\
MortGrowth & 192 & 0.051 & 0.000 & 0.051 & 0.021 & 0.017 \\
$\quad$ Lev & 192 & 16.470 & 1.390 & 17.860 & 9.965 & 4.472 \\
Size & 192 & 3.608 & 4.979 & 8.587 & 7.673 & 0.861 \\
ROA & 192 & 4.650 & 1.010 & 5.660 & 2.892 & 1.381 \\
\hline
\end{tabular}

Figure 1. Weekly Stock Return before and during Covid-19 pandemic

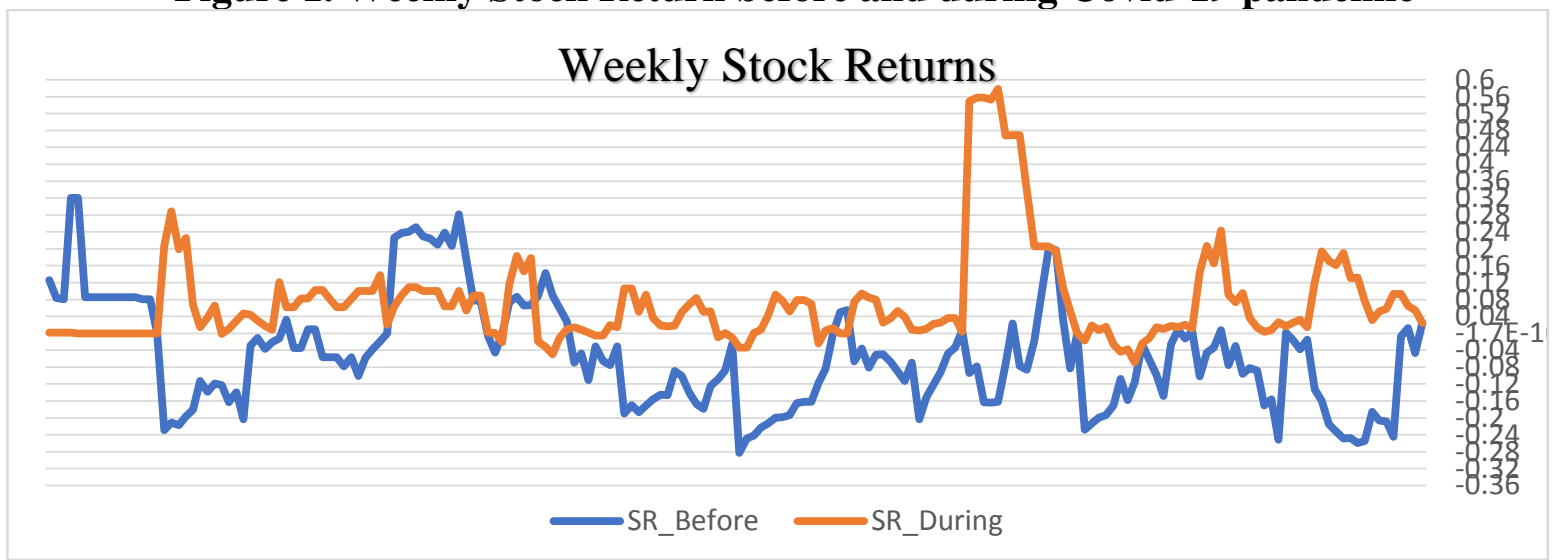

Figure 2. Weekly Stock Return Volatility before and during Covid-19 pandemic Weekly Stock Returns' Volatility

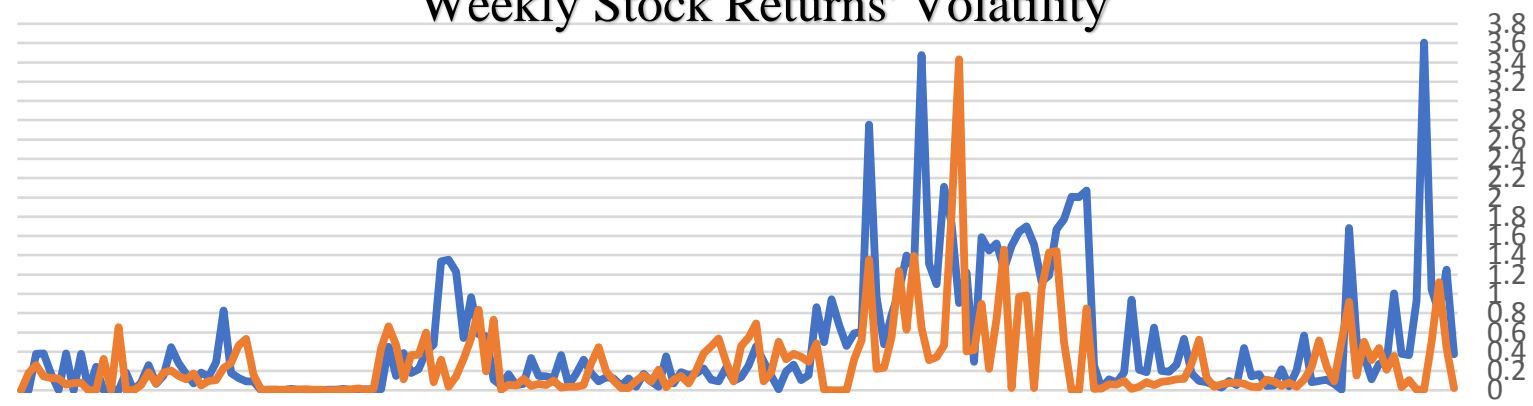
—Vol_During —Vol_Before

In terms of our independent variables, Table 2shows thatthe confirmed new cases (Newcase) and the confirmed new deaths
(NewDeath) have a mean of 2006.8 and 77.563 with standard deviation of 2655 and 83 respectively. During the study period the 
mortality growth rate(MortGrowth), on average, is more than $2 \%$, with minimum (maximum) value of 0 (0.051).

Table 2 also provides the summary statistics ofEgyptian Banks' pre-pandemic characteristics. The leverage ratio (Lev), ranges from 1.390 to 17.860 , with a mean of 9.965 and standard deviation of 4.472 . This indicates thatEgyptian bank's assets, on average, are financed byabout $10 \%$ of debts and remaining $90 \%$ is funded by equity.Bank size (size) has a mean value of 7.673 and standard deviation value of 0.861 , ranging from 4.979 to 8.587 . The return on assets $(R O A)$ ranges from 1.010to 5.660 , with a mean of 2.892 and standard deviation of 1.381, which is a good sign of bank's profitability and the management is interest to maximizetheir shareholder's wealth.

\subsection{Results of Paired sample t-test:}

A paired sample t-test was conducted to discover the statistically significant differences in banks' stock returns and volatility between the two periods (during and pre-covid-19 pandemic periods). Table 3 . shows that the average difference in stock returns before and during covid-19 is 0.126. Since the significance value for change in Stock Returns is less than 0.05, the average value of $-0.126(\mathrm{t}(191)=$ 9.762, $\mathrm{P}=0.000$ ) can be attributed to the Covid-19. So, the first research hypothesis (H1) is accepted and the null hypothesis is refused. Therefore, we conclude that there is a statistically significant difference between Egyptian banks' stock returns in times of covid-19 pandemic and before the pandemic. Moreover, the difference in means of stock returns' volatility before and during covid-19 is 0.187 along with $t$ (191) $=-9.762$ with a significant P-value of less than 0.05. That is, we reject the null hypothesis and accept the alternative one $\mathrm{H} 2$, which indicates that the Egyptian stock returns' volatility during Covid-19 pandemic period is significantly different from pre-Covid-19 pandemic.

\section{Table 3. Paired sample t-Test}

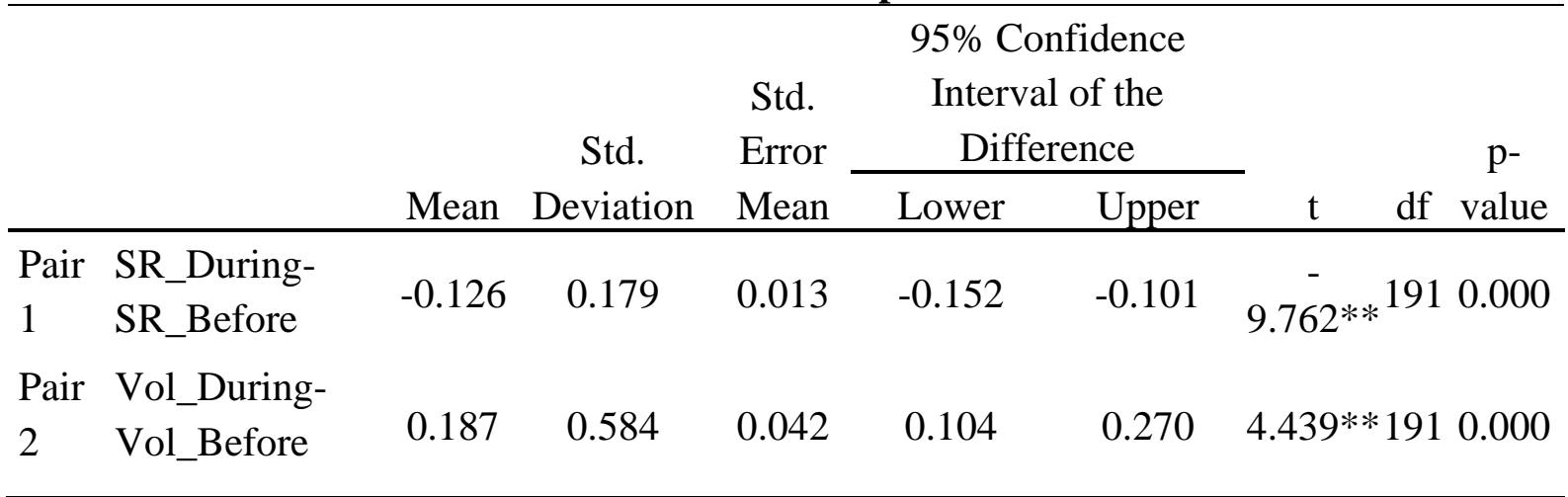

**significant at 0.01 level

\subsection{Results of Correlation Analysis:}

Pearson Correlation is established to assess the association among the variables. Moreover, multicollinearity can be discovered in the correlation matrix and conclude the extent of correlation among the study variables. Table 4 below shows that the maximum correlation is0.793 which is less than 80 percent, this indicates the non-existence of issues related to multi co linearity. For example, Bryman and Cramer (2001) discuss that the correlation between independent variables is considered a problem if it exceeds 80 percent.From the results, it is obvious that the stock return during covid-19 is negatively significant with both confirmed new cases and confirmed new deaths at 0.05 level, and leverage and bank size at 0.01 level, while it is positive significant with the return on assets. However, there is a weak negative insignificant correlation of 0.080 between stock return and mortality growth rate of covid-19. 
Table 4. Pearson's Correlations Matrix
Variables
(1)
(2)
(3)
(4)
(5)
(6)
(7)
(8)

\begin{tabular}{lcccccccc}
\hline l.SR_During & 1 & & & & & & \\
2.Vol_During & -0.013 & 1 & & & & & \\
3.NewCases & $-0.140^{*}$ & $0.137^{*}$ & 1 & & & & \\
4.NewDeaths & $-0.132^{*}$ & $0.126^{*}$ & $0.772^{* *}$ & 1 & & & \\
5.MortGrowth & -0.080 & $0.135^{*}$ & 0.095 & $0.151^{*}$ & 1 & & \\
6.Lev & $-0.353^{* *}$ & $-0.287^{* *}$ & 0.005 & 0.001 & 0.000 & 1 & \\
7.Size & $-0.434^{* *}$ & $0.241^{* *}$ & -0.004 & 0.000 & 0.000 & $0.458^{* *}$ & 1 & \\
8.ROA & $0.367^{* *}$ & $0.257^{* *}$ & -0.007 & -0.001 & 0.000 & $-0.793^{* *}$ & $-0.536^{* *}$ & 1 \\
\hline
\end{tabular}

*. Correlation is significant at the 0.05 level (1-tailed).

**. Correlation is significant at the 0.01 level (1-tailed).

\subsection{Results of RegressionAnalysis}

Table 5and Table 6present the OLS regression modelsresultsto test the impact of Covid-19 variables on Egyptian banks' performance based on our regression model (1) above. The dependent variable in Table 5 for columns (1) to (4) is the weekly stock return. In column (1), (2) and (3), we explore the separate impacts of our explanatory variables related to Covid-19 along with control variables on the weekly stock returns. While, in column (4) all explanatory variables related to Covid-19 are included. The results for all models reveal that both confirmed new cases (NewCases)and confirmed new deaths (NewDeaths) have asignificant and negative impact on banks' stock returns during Covid-19 pandemic (SR_During) at 0.1 level. Moreover, the coefficientof mortality growth rate (MortGrowth) is negative but insignificant with stock returns during the pandemic period (SR_During).

In addition, the results reveal that the bank size (Size) has asignificant and negative impact on banks' stock returns
(SR_During) at 0.01 level, while, the coefficient of bank leverage (Lev) is negative but not significant with stock returns (SR_During). However, the coefficient of return on assets of bank $(R O A)$ is positive and insignificant with stock returns during Covid-19 pandemic (SR_During).

Columns (1) to (4) of Table 6 uses the weekly stock returns' volatility as a dependent variable.We explore the separate impacts of our Covid-19 variables on the weekly stock returns' volatility as in column (1), (2) and (3). The regression results for the first three models reveal that both confirmed new cases (NewCases)and confirmed new deaths (NewDeaths) have a positive coefficientbut insignificant withstock returns' volatility (Vol_During) during Covid-19 pandemic. However, the mortality growth rate (MortGrowth) has a positive and significant effect on the stock returns' volatility during the pandemic (Vol_During). This results are matching with the findings of ClaudiuTiberiuAlbulescu, (2020) and Bakas, (2020) results. 
Table 5. OLS regression analysis: Stock Returns as dependent variable (SR_During)

\begin{tabular}{|c|c|c|c|c|}
\hline & (1) & (2) & (3) & (4) \\
\hline \multirow[t]{2}{*}{ Constant } & $0.421 * *$ & $0.399 * *$ & $0.38 * *$ & $0.452 * *$ \\
\hline & $(0.129)$ & $(0.128)$ & $(0.129)$ & $(0.136)$ \\
\hline \multirow[t]{2}{*}{ NewCases } & $-0.008 *$ & & & $-0.017 *$ \\
\hline & $(0.004)$ & & & $(0.009)$ \\
\hline \multirow[t]{2}{*}{ NewDeaths } & & $-0.009 *$ & & $-0.011 *$ \\
\hline & & $(0.005)$ & & $(0.006)$ \\
\hline \multirow[t]{2}{*}{ MortGrowth } & & & $-.593-$ & -0.569 \\
\hline & & & $(0.479)$ & $(0.493)$ \\
\hline \multirow[t]{2}{*}{ Lev } & -0.005 & -0.005 & $-.005-$ & -0.005 \\
\hline & $(0.004)$ & $(0.004)$ & $(0.004)$ & $(0.004)$ \\
\hline \multirow[t]{2}{*}{ Size } & $-0.051 * * *$ & $-0.050 * * *$ & $-.050 * * *$ & $-0.051 * * *$ \\
\hline & $(0.011)$ & $(0.011)$ & $(0.011)$ & $(0.011)$ \\
\hline \multirow[t]{2}{*}{$R O A$} & 0.004 & 0.004 & 0.004 & 0.004 \\
\hline & $(0.014)$ & $(0.014)$ & $(0.014)$ & $(0.014)$ \\
\hline Observations & 192 & 192 & 192 & 192 \\
\hline Adjusted R-squared & 0.222 & 0.220 & 0.209 & 0.231 \\
\hline
\end{tabular}

Note: Standard errors in parentheses $* * * p<0.01, * * p<0.05, * p<0.1$

On the other hand, column (4) of Table 6 includes all variables related to Covid-19. The results indicate that the confirmed new cases (NewCases), confirmed new deaths (NewDeaths) and mortality growth rate (MortGrowth)have a positive and significant effect on the stock returns' volatility during the pandemic (Vol_During).This finding is consistent with the resutlts of Albulescu, (2020) and Nadeem, (2020).

In addition, it has also observed in Table 6 that the coefficient of bank leverage (Lev) is negative and insignificant with stock returns' volatility (Vol_During). While, bank size (Size) and return on assets have asignificant and positive impact on stock returns' volatility (Vol_During) at 0.01and level, respectively.

\section{Conclusion and Recommendation:}

This Studyexplores how Covid-19 influences risk and return of banks listed on Egyptian stock exchange. We have used two equal periods, sixteen weeks before and during Covid-19 Pandemic, using stock return and stock returns' volatility as dependent variables. We havecompared the data reported before and during pandemic, and we have assessed the impact of covid19 on bank risk and return. The outcomes of our empirical investigation underline the fact that: First, The Egyptian bank's stock returns and stock returns' volatility in the period pre-Covid-19 is better thanthe period duringCovid-19 pandemic. Second, the new confirmed cases and deaths have significant and negative impact on the bank's stock returns. Third, the new confirmed cases, deaths and mortality rate have significant and positive impact on the stock returns volatility. That means that the increasein thenumber declared of confirmed new cases and deathsraisesthe bank risk and lowers stock returns. Forth, the mortality growth rate does not affect bank returns during the recent pandemic period. Finally, the findings in this study imply that declared numbers about Covid-19 cases and deaths do harm bank risk and performance during the pandemic. 
Table 6. OLS regression analysis:Stock Returns' Volatilityas dependent variable (Vol_During)

\begin{tabular}{|c|c|c|c|c|}
\hline & (1) & (2) & (3) & (4) \\
\hline Constant & $\begin{array}{c}-2.522 * * * \\
(0.617)\end{array}$ & $\begin{array}{c}-2.513 * * * \\
(0.609)\end{array}$ & $\begin{array}{c}-2.685 * * * \\
(0.600)\end{array}$ & $\begin{array}{c}-3.074 * * * \\
(0.629)\end{array}$ \\
\hline NewCases & $\begin{array}{c}0.009 \\
(0.018)\end{array}$ & & & $\begin{array}{l}0.178^{*} \\
(0.076)\end{array}$ \\
\hline NewDeath & & $\begin{array}{c}0.020 \\
(0.021)\end{array}$ & & $\begin{array}{l}0.237 * \\
(0.092)\end{array}$ \\
\hline Mortality & & & $\begin{array}{l}4.935^{*} \\
(2.234)\end{array}$ & $\begin{array}{c}6.553 * * \\
(2.284)\end{array}$ \\
\hline Lev & $\begin{array}{l}-0.032 \\
(0.019)\end{array}$ & $\begin{array}{l}-0.032 \\
(0.019)\end{array}$ & $\begin{array}{c}-.032 \\
(0.019)\end{array}$ & $\begin{array}{l}-0.032 \\
(0.019)\end{array}$ \\
\hline Size & $\begin{array}{c}0.382 * * * \\
(0.054)\end{array}$ & $\begin{array}{c}0.383 * * * \\
(0.054)\end{array}$ & $\begin{array}{c}0.383 * * * \\
(0.053)\end{array}$ & $\begin{array}{c}0.387 * * * \\
(0.052)\end{array}$ \\
\hline$R O A$ & $\begin{array}{l}0.152 * \\
(0.066)\end{array}$ & $\begin{array}{l}0.152 * \\
(0.066) \\
\end{array}$ & $\begin{array}{l}0.152 * \\
(0.065) \\
\end{array}$ & $\begin{array}{l}0.155^{*} \\
(0.064) \\
\end{array}$ \\
\hline Observations & 192 & 192 & 192 & 192 \\
\hline Adjusted R-squared & 0.264 & 0.267 & 0.282 & 0.301 \\
\hline
\end{tabular}

Note: Standard errors in parentheses $* * * p<0.01, * * p<0.05, * p<0.1$

\section{References}

1. Alber, N. (2020). The Effect of Coronavirus Spread on Stock Markets: The Case of the Worst 6 Countries. Available at SSRN 3578080. Bansal, T. (2020). Behavioral Finance and COVID-19: Cognitive Errors that Determine the Financial Future. Available at SSRN 3595749.

2. Alfaro, L., Chari, A., Greenland, A., Schott, P., (2020). Aggregate and Firm-Level Stock Returns During Pandemics, in Real Time. NBER working paper 26950.

3. Avkiran, N. K. (2000). Rising productivity of Australian trading banks under deregulation 1986 1995. Journal of Economics and Finance, 24(2), 122-140.
4. Baker, S. R., Bloom, N., Davis, S. J., \& Terry, S. J. (2020). Covidinduced economic uncertainty (No. w26983). National Bureau of Economic Research.

5. Baker, Scott R., Nicholas Bloom, and Stephen J. Terry., (2020). Using Disasters to Estimate the Impact of Uncertainty. No. w27167. National Bureau of Economic Research.

6. Beck and R. Levine, (2004). "Legal Institutions and Financial Development," NBER Working Papers 10417, National Bureau of Economic Research.

7. Cetorelli, N., Gambera, M. (2001), "Banking market structure, financial dependence and growth: international evidence from industry data", Journal of Finance, 56, 617648. 
8. Hassan, Tarek Alexander and Hollander, Stephan and van Lent, Laurence and Schwedeler, Markus and Tahoun, Ahmed.(2020), "Firmlevel Exposure to Epidemic Diseases: Covid-19, SARS, and H1N1", "National Bureau of Economic Research institution ",

9. Khan, Karamat\& Zhao, Huawei \& Zhang, Han \& Yang, Huilin\& Haroon, Muhammad \&Jahanger, Atif. (2020). The Impact of COVID19 Pandemic on Stock Markets: An Empirical Analysis of World Major Stock Indices. The Journal of Asian Finance, Economics and Business. 7. 463-474. 10.13106/jafeb.2020.vol7.no7.463. 10. Liu, HaiYue\&Manzoor, Aqsa \& Wang, CangYu\& Zhang, Lei \&Manzoor, Zaira. (2020). The COVID-19 Outbreak and Affected Countries Stock Markets Response. International Journal of Environmental Research and Public Health.

11. Mazur, Mieszko\& Dang, Man \& Vega, Miguel. (2020). COVID-19 and the march 2020 stock market crash. Evidence from S\&P1500. Finance Research Letters.

12. Narayan, P.K., and Sharma, S., (2011). New evidence on oil price and firm returns Journal of Banking and

Finance doi:10.1016/j.bankfin.2011.05.010

13. Nguyen, V. C. (2020). Government Ability, Bank-Specific Factors and Profitability-An insight from banking sector of Vietnam.

14. Ramelli, Stefano and Wagner, Alexander F., Feverish Stock Price
Reactions to COVID-19 (June 16, 2020). Forthcoming, Review of Corporate Finance Studies, Swiss Finance Institute Research Paper No. 20-12,

15. Sansa, N. A. (2020). The Impact of the COVID-19 on the Financial Markets: Evidence from China and USA. Electronic Research Journal of Social Sciences and Humanities.

16. Song, HyoungJu, JihwanYeon, and Seoki Lee. (2020) "Impact of the COVID-19 pandemic: Evidence from the US restaurant industry." International Journal of Hospitality Management 92,Vol:2

17. World Health Organization. Office of Library and Health Literature Services. (2020). 